\title{
Orofacial Granulomatosis - A Rare Case Report with Review of Literature
}

\author{
Sujatha S Reddy ${ }^{1}$, N Rakesh ${ }^{2}$, Thanuja Ramadoss ${ }^{3}$, Deepa Jatti ${ }^{3}$
}

\begin{abstract}
${ }^{1}$ MDS Professor, Departent of Oral Medicine, Diagnosis and Radiology, M.S.Ramaiah Dental College \& Hospital,Msrit Post, New Bel Road, Bangalore. Karnataka, India.

${ }^{2}$ MDS Associate Professor, Departent of Oral Medicine, Diagnosis and Radiology, M.S.Ramaiah Dental College \& Hospital, Msrit Post, New Bel Road, Bangalore. Karnataka, India.

${ }^{3}$ PG Students, Departent of Oral Medicine, Diagnosis and Radiology, M.S.Ramaiah Dental College \& Hospital, Msrit Post, New Bel Road, Bangalore. Karnataka, India.
\end{abstract}

Correspondence:

Dr. Sujatha S Reddy,

Departent of Oral Medicine, Diagnosis and Radiology,

M.S.Ramaiah Dental College \& Hospital,

Msrit Post, New Bel Road, Bangalore.

Karnataka, India.

E-mail id:s_sujathajanardhan@yahoo.com

\begin{abstract}
The term orofacial granulomatosis (OFG) is a descriptive term used for granulomatous disorders affecting the face and oral cavity, which can occur for a variety of reasons resulting in significant morbidity. It is characterised by persistent swelling that may involve one or both the lips and /or recurrent ulcers and a variety of other orofacial features. Medical history is very important in the diagnosis of OFG as medical condition like Crohn's disease can also present an extra intestinal manifestation of OFG. Exclusion of other entities like sarcoidosis, mycobacterial infections, foreign body reactions and biopsy helps to establish a correct diagnosis. Herein we report a case of OFG in a 55 year old female patient with review of literature.
\end{abstract}

Key words: Orofacial granulomatosis, lip oedema, gingival enlargement, intralesional steroids. 


\section{Introduction}

Wiesenfeld (1) in 1985 introduced OFG and since then it has been a well accepted and unifying term assembling a variety of clinical presentations that on histopathological examination reveal the presence of nonspecific granulomatous inflammation. It is a nonspecific, descriptive term encompassing a variety of conditions that exhibit similar clinical and microscopic features. If all possible causes have been ruled out, OFG is used as a clinical diagnosis of exclusion (2).The clinical presentation of OFG is highly variable, the most consistent finding being persistent, painless swelling of the orofacial tissues. Lips are the most frequent site of involvement and other intraoral sites commonly affected are the tongue, gingiva and buccal mucosa. OFG is a non life threatening disease of unknown etiology that may need further clinical, hematological, radiographic and endoscopic investigation to arrive at a correct diagnosis. Cheilitis granulomatosa is a subtype of OFG in which there is persistent, nontender swelling restricted to one or both the lips (3). Early diagnosis is important as it provides better prognosis. The first goal of management should be identification of the initiating cause, however this can be difficult as often the reason is elusive at times and there can be spontaneous remission in a few cases.

\section{Case report}

A 55-year-old female patient reported with a complaint of swelling of her upper and lower lips since 2 years and gingival enlargement since 8 months. Her past dental history revealed extraction of maxillary anterior teeth because of mobility and gingival enlargement. There was no contributory medical history, drug use and family background. Extraoral examination revealed diffuse enlargement of the right and left cheeks, and upper and lower lips. The swelling of the cheek was firm and indurated. The contour of the upper and lower lips was lost, were inflamed, everted, fissured and crustated (Fig.1). On palpation the upper and lower lips were firm in consistency

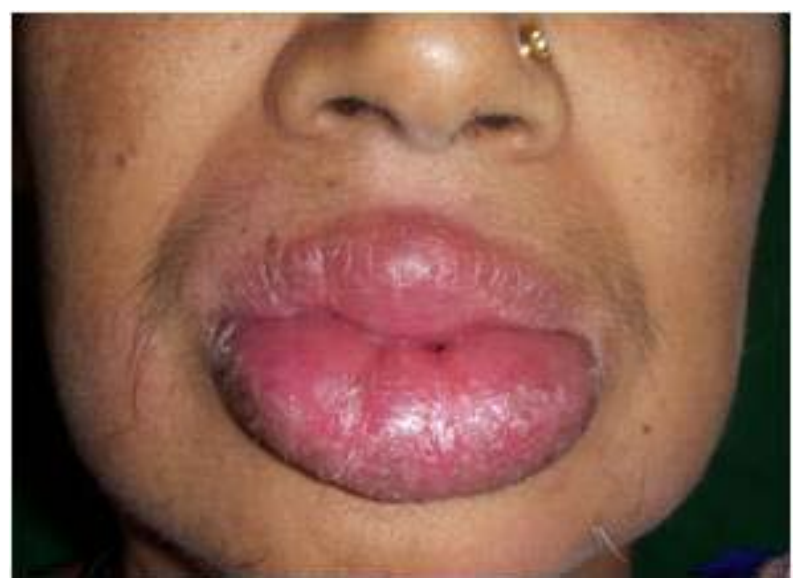

Fig. 1. Enlargement of the cheeks, upper and lower lips. The lips are inflamed and lower lip is everted and non tender. Intraoral examination revealed gingival enlargement of the maxillary and mandibular arches (Fig.2). Marginal, interdental and attached gingiva was enlarged and only the incisal edges of the mandibular incisors were visible whereas half of the maxillary premolar and molar teeth were covered by gingiva (Fig.3).

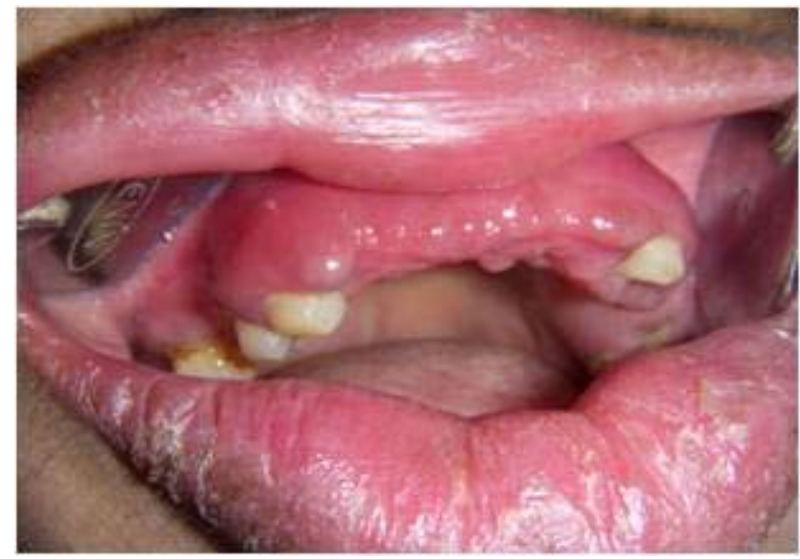

Fig. 2. Enlarged gingiva irt maxillary premolar and molar region covering half of the crowns.

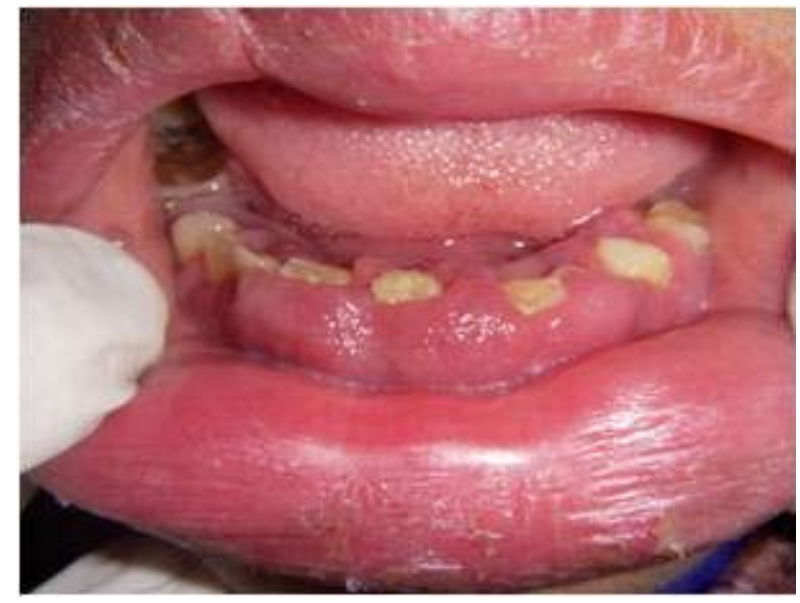

Fig. 3. Enlarged gingiva irt mandibular teeth covering $2 / 3 \mathrm{rd}$ of the crowns with cobble stone appearance of lower labial mucosa.

The gingiva was inflamed, soft in consistency, non tender and no bleeding on probing was present. The lower labial mucosa showed cobble stone appearance (Fig.3). Hard tissue examination revealed few missing teeth, generalized attrition and grade I mobility of all mandibular anterior teeth. Angioneurotic edema, Crohn's disease, sarcoidosis, tuberculosis and cheilitis granulomatosa were considered under differential diagnosis.

Incisional biopsy from the lower labial mucosa was performed and histopathological examination revealed the presence of non caseating granulomas composed of epitheloid histiocytes and giant cells with a peripheral rim of lymphocytes. Routine hematological and biochemical investigations were done (Table 1). On endoscopic examination to rule out Crohn's disease, the intestinal mucosa appeared normal with no erythema or ulcerations. 


\begin{tabular}{|l|l|l|}
\hline Investigations & Results & Reference range \\
\hline Haemoglobin & $11.2 \mathrm{gm} / \mathrm{dl}$ & $14-16 \mathrm{gm} / \mathrm{dl}$ \\
Total WBC count & $9,300 / \mathrm{mm} 3$ & $4000-11000 / \mathrm{mm} 3$ \\
Neutrophils & $56 \%$ & $40-74 \%$ \\
Eosinophils & $4 \%$ & $1-7 \%$ \\
Monocytes & $3 \%$ & $1-9 \%$ \\
Lymphocytes & $35 \%$ & $1.5-41 \mathrm{lakhs} / \mathrm{mm}^{3}$ \\
Platelet count & $2,65,000$ lakhs $/ \mathrm{mm}^{3}$ & \\
Peripheral smear & Normocytic normochromic & $10-20 \mathrm{~mm} / \mathrm{hr}$ \\
ESR & $18 \mathrm{~mm} / \mathrm{hr}$ & \\
\hline AFB staining & Negative & $5-89 \mathrm{u} / \mathrm{ltr}$ \\
\hline SACE level & $52 \mathrm{u} / \mathrm{ltr}$ & \\
\hline
\end{tabular}

WBC-White blood cells

ESR-Erythrocyte sedimentation rate

AFB-Acid fast staining bacilli

SACE - Serum angiotensinogen converting enzyme inhibitor

Table 1. Diagnostic workup in OFG

The chest radiograph appeared normal. Patch testing was done for commonly used food products and cosmetics and the results were negative.

A diagnosis of OFG was made based on correlation of the histopathological and laboratory findings. The patient was treated with triamicinolone $40 \mathrm{mg} / \mathrm{ml}$ intralesionaly twice a week for 4 weeks followed by slow tapering dose of $20 \mathrm{mg}$ for 2 weeks, $10 \mathrm{mg}$ for 2 weeks and then the drug was discontinued thereafter. Following this there was considerable reduction in the size of the lips and cheeks at the end of 8 weeks. Subsequently, the patient is under follow up since 18 months and has shown no signs of recurrence.

\section{Discussion}

OFG is an uncommon disease affecting the oral and perioral structures of the face. It is normally seen in the second decade of life and has a female predilection. Zimmer etal (4) in a literature review of 262 patients reported a female predilection of $56 \%$. The precise etiology is unknown but a genetic predisposition may be possible (5). A cell mediated hypersensitivity reaction is predicted as an etiologic factor because of the presence of activated helper $\mathrm{T}$ lymphocytes expressing interleukin-2 receptors in these lesions (6). It is also postulated that the cytokine production by lymphocytic clone could be responsible for the formation of granulomas in this condition (7).

The clinical presentation of OFG is variable. The most frequent presentation is a nontender, persistent swelling involving one or both the lips. Rarely, superficial amber vesicles resembling lymphangioma may be found. When the tongue is involved fissures, edema and pares- thesia may be present. The involved buccal and labial mucosa show cobble stone appearance. Gingival swelling and tenderness may be present (1). Mignogna etal (8) reported a monosymptomatic onset with generalized hyperplastic gingivitis that preceded other facial and mucosal lesions.

As the clinical and histopathological features of OFG can be produced by a variety of underlying causes the patient should be evaluated for other granulomatous conditions like Crohn's disease, sarcoidosis, mycobacterial infection (tuberculosis, leprosy, and atypical mycobacterium), foreign body reaction and contact allergy (2). IgE levels and patch test may be of diagnostic value when hypersensitivity reaction is suspected. Exclusion of sarcoidosis can be done by chest radiograph, serum angiotensinogen converting enzyme level and eventually Kveim test. Tuberculosis should be ruled out by acid fast bacillus staining and chest radiographs. 10\%-37\% of patients with OFG have been found to have Crohn's disease and oral lesions may precede the intestinal involvement (8). Hence, endoscopy and colorectal biopsy are justified when signs and symptoms of gastrointestinal disturbance is observed. All the above investigations were carried out in our patient to rule out the above mentioned conditions. Histopathological examination shows chronic inflammatory cell infiltrate particularly peri and paravascular aggregation of lymphocytes, plasma cells, non caseating granuloma formations with epitheloid cells and Langhans type of giant cells.

A variety of drugs have been tried in the treatment of OFG but the most preferred mode of treatment is systemic corticosteroids. Glucocorticoids effectively suppress the activated $\mathrm{T}$ - helper cell process occurring at 
the site of the disease. The usual therapy is prednisolone $1 \mathrm{mg} / \mathrm{kg}$ for 4-6 weeks followed by slow tapering over 2-3 months. Sakuntabhai etal (9) suggested treatment with high volume of steroids of 3-10 ml, gave a disease free period of 10 months but the major disadvantage was the large volume which produced considerable pain and discomfort to the patient during the administration of the drug. In a pilot study conducted by Mignogna etal (10), small volume, high- concentration of extended release triamicinolone injection appeared to be effective. In our patient the intralesional use of high volume triamicinolone in a tapering dose over a period of eight weeks resulted in resolution of the lesion with no recurrence during the follow up period of eighteen months. Drugs like salazosulfapyridine, hydroxychloroquine, azathioprine, dapsone, methotrexate and thalidomide have been tried with partial success. Surgical recontouring (reduction chiloplasty) is not frequently used as there is an increased risk of recurrence. Prognosis is variable and is best in early diagnosed cases (1).

Dentists are the first among health care professionals to be consulted for diagnosis and treatment of this disorder. Hence, the dentists should be familiar with all the possible granulomatous conditions affecting the orofacial region.

\section{References}

1. Wiesenfeld D, Ferguson MM, Mitchell DN, MacDonald DG, Scully C, Cochran K, et al. Oro-facial granulomatosis--a clinical and pathological analysis. Q J Med. 1985; 54:101-13.

2. Alawi F. Granulomatous diseases of the oral tissues: differential diagnosis and update. Dent Clin North Am. 2005; 49:203-21.

3. El-Hakim M, Chauvin P. Orofacial granulomatosis presenting as persistent lip swelling: review of 6 new cases. J Oral Maxillofac Surg. 2004; 62:1114-7.

4. Zimmer WM, Rogers RS 3rd, Reeve CM, Sheridan PJ. Orofacial manifestations of - Rosenthal syndrome. A study of 42 patients and review of 220 cases from the literature. Oral Surg Oral Med Oral Pathol. 1992; 74:610-9.

5. Smeets E, Fryns JP, Van den Berghe H. Melkersson-Rosenthal syndrome and de novo autosomal $\mathrm{t}(9 ; 21)(\mathrm{p} 11 ; \mathrm{p} 11)$ translocation. Clin Genet. 1994; 45:323-4.

6. Shams MG, Motamedi MH, Azizi T. Orofacial granulomatosis of the lower lip and cheek: report of a case. Oral Surg Oral Med Oral Pathol Oral Radiol Endod. 2007; 104:e42-4.

7. De Quatrebarbes J, Cordel N, Bravard P, Lenormand B, Joly P. Miescher's cheilitis and lymphocytic clonal expansion: 2 cases. Ann Dermatol Venereol. 2004; 131:55-7.

8. Mignogna MD, Fedele S, Lo Russo L, Lo Muzio L. Orofacial granulomatosis with gingival onset. J Clin Periodontol. 2001; 28:692-6.

9. Sakuntabhai A, MacLeod RI, Lawrence CM. Intralesional steroid injection after nerve block anesthesia in the treatment of orofacial granulomatosis. Arch Dermatol. 1993;129:477-80.

10. Mignogna MD, Fedele S, Lo Russo L, Adamo D, Satriano RA. Effectiveness of small-volume, intralesional, delayed-release triamcinolone injections in orofacial granulomatosis: a pilot study. J Am Acad Dermatol. 2004; 51:265-8.

\section{Acknowledgement}

I would like to thank our Principal and Prof Dr. H. N. Shama Rao for his support and guidance 